\title{
Economic Ordering Policies of Linearly Time-Dependent Deteriorating Items with an Exponential Demand Rate under Credit Financing
}

\section{R. P. Tripathi ${ }^{1 *}$, H. S. Shukla ${ }^{2}$, Vivek Shukla ${ }^{3}$ and Sushil Kumar Yadav ${ }^{3}$}

${ }^{1}$ Department of Mathematics, Graphic Era University, Dehradun, India

${ }^{2}$ Department of Mathematics, DDU Gorakhpur University, Gorakhpur, Uttar Pradesh, India

${ }^{3}$ Department of Mathematics, ITM, Gida, Gorakhpur, Uttar Pradesh, India

\begin{abstract}
This paper presents the economic ordering policies of linearly time-dependent deteriorating items with an exponential demand rate in the presence of trade credit using Discount Cash Flow (DCF) approach. Mathematical models are derived under two different situations: Case (1) Instantaneous cash flows, and Case (2) Fixed credit period. The expressions for on inventory systems present the value of all future cash flows are derived for these two cases. The main purpose of this paper is to obtain the optimal (minimum) present values of all future cash flows for both cases. The sensitivity analysis is given for the applicability of the purposed model. Mathematical software is used for finding numerical values of optimal cycle time with different discount rate and different credit period.
\end{abstract}

Keywords: Exponential demand rate; Linearly time dependent deterioration rate; Credit financing; Discount cash flow

\section{Introduction}

The objective of inventory management deals with minimization of the inventory cost. Thus it is necessary to determine the optimal stock and optimal time of inventory to meet the future demand. Demand is a major factor in inventory management. The four main types of demand are assumed in the inventory models i.e. constant demand, time-dependent demand, probabilistic demand and stock-dependent demand. Inventory models dealing with time dependent demand have more relevance in the present situation. At initial stage the demand rate of the item is assumed to be constant. However, demand varies with time in market situations.

Most of the inventory models assumed that items can be stored indefinitely to meet the future demand. However, the certain types of items deteriorate in the course of time and thus are unstable. For example, the commonly used items like fruits, green vegetables, food stuffs, perfumes, alcohol, gasoline, radioactive substances, electronic components etc. where deterioration is often observed during their normal storage period. Therefore the impact of deterioration on modeling of an inventory system cannot be ignored. Deterioration refers to the spoilage, damage, dryness, and vaporization etc. of the products. The products like food stuffs, human blood, photographic films etc., having maximum usable life time are called perishable products and the products like alcohol, radioactive substances, gasoline etc. having no self-life at all are called decaying products.

Goyal [1], developed a single item inventory model under permissible delay in payments. Chung [2], simplified the search of the optimal solution for the problem explored by the Goyal [1]. Goyal's model [1] was corrected by Dave [3], by assuming the fact that the selling price is necessarily higher than its purchase cost. Aggarwal and Jaggi [4], extended Goyal's [1] model for deteriorating items. Jamal et al. [5], further generalized the model to allow for shortages and deterioration. Liao et al. [6], presented an inventory model for stock-dependent demand rate when a delay in payment is permissible. Teng [7], provided an alternative conclusion from Goyal's [1], and mathematically proved that it makes economic sense for a well-established buyer to order less quantity and take the benefits of the permissible delay more frequently. Chang et al. [8], then extended Teng's model [7], and established an
EOQ model for deteriorating items in which the supplier provides a permissible delay to the seller of the order quantity is greater than or equal to a predetermined quantity. Various types of inventory models for items deteriorating at a constant rate were discussed by large number of researchers like Teng et al. [9], Hwang and Shinn [10], Tripathy and Mishra [11], Tripathi and kumar [12], Jamal et al. [13] and others. Economic Order Quantity (EOQ) model with trade credit financing for non-decreasing demand was discussed by Teng et al. [14].

All the above researchers established there EOQ inventory models under trade credit financing by assuming that the demand rate and deterioration both are constant. But in real life demand and deterioration rates both are not always constant but both are time dependent. Tripathy and Mishra [15] developed an inventory model for weibull time-dependent demand rate with completely backlogged considering four different situations. Hung [16], established an inventory model with generalized type demand, deterioration and back order rates. Sana [17] developed optimal selling price and lot size with time varying deterioration and partial backlogging. Article [17] dealt with an EOQ model over an infinite time horizon for permissible items where demand is price dependent and partial back order is permitted. Khanara et al. [18], presented an EOQ model for a deteriorating item with time dependent quadratic demand under permissible delay in payment. An EOQ model with delay in payments and time varying deterioration rate was discussed by Sarkar [19].

Inflation is an important factor in the study of inventory model. Ouyang et al. [20], developed an EOQ model for deteriorating items

${ }^{*}$ Corresponding author: R. P. Tripathi, Head of the Department, Department of Mathematics, Graphic Era University, Dehradun 248001, India, E-mail: tripathi_rp0231@rediffmail.com

Received October 02, 2012; Accepted November 22, 2012; Published Novembe 24, 2012

Citation: Tripathi RP, Shukla HS, Shukla V, Yadav SK (2012) Economic Ordering Policies of Linearly Time-Dependent Deteriorating Items with an Exponential Demand Rate under Credit Financing. J Applied Computat Mathemat 1:119. doi:10.4172/2168-9679.1000119

Copyright: (c) 2012 Tripathi RP, et al. This is an open-access article distributed under the terms of the Creative Commons Attribution License, which permits unrestricted use, distribution, and reproduction in any medium, provided the original author and source are credited. 
Citation: Tripathi RP, Shukla HS, Shukla V, Yadav SK (2012) Economic Ordering Policies of Linearly Time-Dependent Deteriorating Items with an Exponential Demand Rate under Credit Financing. J Applied Computat Mathemat 1:119. doi:10.4172/2168-9679.1000119

Page 2 of 5

under trade credits considering a cash discount to motivate faster payment and reduce credit expenses. Yang et al. [21], established an inventory model under inflation for deteriorating items with stockdependent consumption rate and partial backlogging shortages. Chung and Liao [22], established the optimal ordering policy of the EOQ model under trade credit depending on the ordering quantity from, the DCF approach. This paper [22] incorporated all concepts of Discount Cash-Flows (DCF) approach, trade credit and the quantity ordered and developed a new inventory model to generalized Chung [23] model. Various types of inventory models connecting to inflation and Discount Cash Flows (DCF) approach were discussed by large number of researchers like Liao et al. [6], Dye et al. [24], Hsieh and Dye [25], Chung and Liao [26], Hill and Pakkala [27], Jaggi et al. [28], Jaggi et al. [29], etc. The main objective of this study is to obtain minimum present value of the all future cash flow, cycle time and order quantity for different values of credit period.

The rest of this paper is organized as follows: In the next section notations and assumptions are given followed by mathematical formulation. Optimal solution is given in Numerical Examples section followed by sensitivity analysis is in Sensitivity Analysis section. Finally conclusion and future research directions are given at the last in Conclusion \& future research section.

\section{Notations and Assumptions}

The following notations are used throughout the manuscript:

$\mathrm{T}$ : The inventory cycle time

Q: The order quantity

$\mathrm{A}_{1}$ : Ordering cost per order

$\mathrm{m}$ : The credit period

c: Unit cost of the item

ic: The out of pocket inventory carrying cost per unit time

r: The discount rate per unit time

$I(t)$ : The inventory level at time $\mathrm{t}$

$T_{1}$ : Optimal cycle time for case (1)

$T_{2}$ : Optimal cycle time for case (2)

$Q_{1}$ : Optimal ordering quantity for case (1)

$Q_{2}$ : Optimal ordering quantity for case (2)

$Z_{1}(T)$ : The present value of all future cash flows for case (1)

$Z_{2}(T)$ : The present value of all future cash flows for case (2)

$Z_{1}\left(T_{1}\right)$ : Optimal values of present values of all future cash flows for case (1)

$Z_{2}\left(T_{2}\right)$ : Optimal values of present values of all future cash flows for case (2)

$\theta=\theta(t)=(\alpha+\beta t):$ Time dependent deterioration rate $0<\alpha<1,0<\beta<1, \alpha>\beta$.

$D=D(t)=\lambda e^{\gamma t}:$ Time dependent demand rate $\lambda>0,0<\gamma<1$

In addition the following assumptions are being made throughout the manuscript:

a) Replenishment is instantaneous. b) Shortages are not allowed.

c) Lead time is zero.

d) Deterioration rate is linearly time-dependent i.e. $\theta=\theta(t)=(\alpha+\beta t), \quad 0<\alpha<1,0<\beta<1, \alpha>\beta$

e) Demand rate is exponential time-dependent i.e. $D=D(t)=\lambda e^{\gamma t}$, $\lambda>0,0<\gamma<1$

\section{Mathematical Formulation}

The level of inventory $I(t)$ at time $t$ is depleted due to deterioration and also due to demand only. The differential equation describing the instantaneous state of $I(t)$ over $(0, \mathrm{~T})$ is given by

$$
\frac{d I(t)}{d t}+(\alpha+\beta t) I(t)=-\lambda e^{\gamma t}, 0 \leq t \leq T
$$

With boundary condition I ( $\mathrm{T})=0$, the solution of $(1)$ is

$$
\begin{aligned}
& I(t)=\lambda\left\{(T-t)+\frac{A}{2}\left(T^{2}-t^{2}\right)+\frac{B}{3}\left(T^{3}-t^{3}\right)\right\} e^{-\alpha t-\frac{\beta}{2} t^{2}}, \\
& A=\alpha+\gamma, B=\frac{(\alpha+\gamma)^{2}+\beta}{2} \\
& Q=I(0)=\lambda\left(T+\frac{A}{2} T^{2}+\frac{B}{3} T^{3}\right)
\end{aligned}
$$

The total demand in one cycle is $\int_{0}^{T} \lambda e^{\gamma t} d t$ and $\mathrm{D}(\mathrm{T})$ is the number of units that deteriorated during one cycle. Therefore

$$
D(T)=Q-\int_{0}^{T} \lambda e^{\gamma t} d t=\lambda\left(\frac{A}{2} T^{2}+\frac{B}{3} T^{3}\right)
$$

We discuss below two cases on the trade credit terms by using the DCF approach.

\section{Case 1: Instantaneous cash flows}

In this case we present the DCF approach to the simple inventory model of time dependent deteriorating items under instantaneous inventory holding cost. Thus at the beginning of each cycle there will be cash out flows of ordering cost A1 and purchase cost cQ. Also, since the inventory carrying cost is proportional to the value of inventory, the out of pocket inventory carrying cost per unit time at $\mathrm{t}$ is ic $I(t)$ . The present value of the out of pocket carrying cost is obtained by continuous discounting ic $I(t) e^{-r t}[23]$. Hence, the present value of cash flow for the first order cycle $Z_{1}(\mathrm{~T})$, is

$$
\begin{aligned}
& z_{1}(T)=\mathrm{A}_{1}+c Q+i c \int_{0}^{T} I(t) e^{-r t} d t \\
= & \mathrm{A} 1+c \lambda\left(T+\frac{A}{2} T^{2}+\frac{B}{3} T^{3}\right)+i c \lambda\left\{\frac{T^{2}}{2}+\left(\frac{A}{3}-\frac{A^{\prime}}{6}\right) T^{3}+\left(\frac{B+B^{\prime}}{3}-\frac{A A^{\prime}}{4}\right) T^{4}+\frac{B B^{\prime}}{9} T^{6}\right\}
\end{aligned}
$$

Where $A^{\prime}=\alpha+\gamma, B^{\prime}=\frac{(\alpha+\gamma)^{2}-\beta}{2}$

The present value of all future cash flows is

$$
Z_{1}(T)=\sum_{n=0}^{\infty} z_{1}(T) e^{-n r T}=\frac{z_{1}(T)}{1-e^{-r T}}
$$

To find closed form solution putting $e^{-r T} \approx 1-r T$ approximately, we get

$$
\begin{aligned}
& Z_{1}(T)=\frac{1}{r}\left\{\frac{\mathrm{A}_{1}}{\mathrm{~T}}+c \lambda\left(1+\frac{A}{2} T+\frac{B}{3} T^{3}\right)\right\} \\
& +\frac{i c \lambda}{r}\left\{\frac{T}{2}+\left(\frac{A}{3}-\frac{A^{\prime}}{6}\right) T^{2}+\left(\frac{B+B^{\prime}}{3}-\frac{A A^{\prime}}{4}\right) T^{3}+\left(\frac{A B^{\prime}-A^{\prime} B}{6}\right) T^{4}+\frac{B B^{\prime}}{9} T^{5}\right\}
\end{aligned}
$$


The optimum value of $\mathrm{T}=T_{1}$ can be obtained from the solution of the equation $\frac{d Z_{1}(T)}{d T}=0$

$$
\begin{aligned}
& \frac{d Z_{1}(T)}{d T}=\frac{1}{r}\left\{-\frac{\mathrm{A}_{1}}{\mathrm{~T}^{2}}+c \lambda\left(\frac{A}{2}+\frac{2 B}{3} T^{2}\right)\right\} \\
& +\frac{i c \lambda}{r}\left\{\frac{1}{2}+2\left(\frac{A}{3}-\frac{A^{\prime}}{6}\right) T+3\left(\frac{B+B^{\prime}}{3}-\frac{A A^{\prime}}{4}\right) T^{2}+4\left(\frac{A B^{\prime}-A^{\prime} B}{6}\right) T^{3}+\frac{5 B B^{\prime}}{9} T^{4}\right\} \\
& \frac{d^{2} Z_{1}(T)}{d T^{2}}=\frac{1}{r}\left(\frac{2 \mathrm{~A}_{1}}{\mathrm{~T}^{3}}+\frac{2 B c \lambda}{3}\right) \\
& +\frac{i c \lambda}{r}\left\{2\left(\frac{A}{3}-\frac{A^{\prime}}{6}\right)+6\left(\frac{B+B^{\prime}}{3}-\frac{A A^{\prime}}{4}\right) T+12\left(\frac{A B^{\prime}-A^{\prime} B}{6}\right) T 2+\frac{20 B B^{\prime}}{9} T^{3}\right\}>0
\end{aligned}
$$

For extreme (minimum) $\frac{d Z_{1}(T)}{d T}=0$, we obtain

$$
\begin{aligned}
& \left\{-\frac{A_{1}}{T^{2}}+c \lambda\left(\frac{A}{2}+\frac{2 B}{3} T\right)\right\} \\
& +i c \lambda\left\{\frac{1}{2}+2\left(\frac{A}{3}-\frac{A^{\prime}}{6}\right) T+3\left(\frac{B+B^{\prime}}{3}-\frac{A A^{\prime}}{4}\right) T^{2}+4\left(\frac{A B^{\prime}-A^{\prime} B}{6}\right) T^{3}+\frac{5 B B^{\prime}}{9} T^{4}\right\}=0
\end{aligned}
$$

or

$$
\begin{aligned}
& 20 i B B^{\prime} T^{6}+24 i\left(A B^{\prime}-A^{\prime} B\right) T^{5}+3 i\left\{12\left(B+B^{\prime}\right)-9 A A^{\prime}\right\} T^{4} \\
& +\left\{24 B+2 i\left(12 A-6 A^{\prime}\right)\right\} T^{3}+18(A+i) T^{2}-\frac{36 A_{1}}{c \lambda}=0
\end{aligned}
$$

Solving equation (9) for $\mathrm{T}$, we get optimal (minimum) cycle time $T=T_{1} \&$ corresponding optimal (minimum) order quantity

$$
Q=Q_{1}=\lambda\left(T_{1}+\frac{A}{2} T_{1}^{2}+\frac{B}{3} T_{1}^{3}\right)
$$

And corresponding optimal (minimum) value of all future cashflows $Z_{1}(T)=Z_{1}\left(T_{1}\right)$ can be obtained from equation (6).

\section{Case 2: Fixed credit period}

In this case the credit being fixed. It means that the customer pays the full purchase amount on the last day of the credit period. Thus, in this case the present value of cash-flows for one cycle $\mathrm{Z} 2(\mathrm{~T})$ is

$$
\mathrm{Z}_{2}(\mathrm{~T})=\mathrm{A}_{1}+c Q e^{-r m}+i c \int_{0}^{T} I(t) e^{-r t} d t
$$

Using equation (2) and (3) in above equation, we get

$$
\begin{aligned}
& z_{2}(T)=A_{1}+c \lambda\left(T+\frac{A}{2} T^{2}+\frac{B}{3} T^{3}\right) e^{-r m} \\
& +i c \lambda\left\{\frac{T^{2}}{2}+\left(\frac{A}{3}-\frac{A^{\prime}}{6}\right) T^{3}+\left(\frac{B+B^{\prime}}{3}-\frac{A A^{\prime}}{4}\right) T^{4}+\left(\frac{A B^{\prime}-A^{\prime} B}{6}\right) T^{5}+\frac{B B^{\prime}}{9} T^{6}\right\}
\end{aligned}
$$

The present value of all future cash-flows is

$$
Z_{2}(T)=\sum_{n=0}^{\infty} z_{2}(T) e^{-n r T}=\frac{z_{2}(T)}{1-e^{-r T}}
$$

To find closed form solution putting $e^{-r T} \approx 1-r T$ approximately, we get

$$
\begin{aligned}
& Z_{2}(T)=\frac{1}{r}\left\{\frac{A_{1}}{T}+c \lambda\left(1+\frac{A}{2} T+\frac{B}{3} T^{2}\right)(1-r m)\right\}+\frac{i c \lambda}{r}\left\{\frac{T}{2}+\left(\frac{A}{3}-\frac{A^{\prime}}{6}\right) T^{2}+\left(\frac{B+B^{\prime}}{3}-\frac{A A^{\prime}}{4}\right) T^{3}\right\} \\
& +\left(\frac{A B^{\prime}-A^{\prime} B}{6}\right) T^{4}+\frac{B B^{\prime}}{9} T^{5}
\end{aligned}
$$

The optimum value of $\mathrm{T}=\mathrm{T}_{2}$ can be obtained from the solution of the equation

$$
\begin{aligned}
& \frac{d Z_{2}(T)}{d T}=0 \\
& \frac{d Z_{2}(T)}{d T}=\frac{1}{r}\left\{-\frac{A_{1}}{T^{2}}+c \lambda\left(\frac{A}{2}+\frac{2 B}{3} T\right)(1-r m)\right\}+\frac{i c \lambda}{r}\left\{\frac{1}{2}+2\left(\frac{A}{3}-\frac{A^{\prime}}{6}\right) T+3\left(\frac{B+B^{\prime}}{3}-\frac{A A^{\prime}}{4}\right) T^{2}\right\} \\
& +2\left(\frac{A B^{\prime}-A^{\prime} B}{3}\right) T^{3}+\frac{5 B B^{\prime}}{9} T^{4} \\
& \frac{d^{2} Z_{2}(T)}{d T^{2}}=\frac{1}{r}\left\{\frac{2 A_{1}}{T^{3}}+\frac{2 B c \lambda}{3}(1-r m)\right\} \\
& +\frac{i c \lambda}{r}\left\{2\left(\frac{A}{3}-\frac{A^{\prime}}{6}\right)+6\left(\frac{B+B^{\prime}}{3}-\frac{A A^{\prime}}{4}\right) T+12\left(\frac{A B^{\prime}-A^{\prime} B}{6}\right) T^{2}+\frac{20 B B^{\prime}}{9} T^{3}\right\}>0
\end{aligned}
$$

For extreme (minimum) $\frac{d Z_{2}(T)}{d T}=0$, we obtain

$\left\{-\frac{A_{1}}{T^{2}}+c \lambda\left(\frac{A}{2}+\frac{2 B}{3} T\right)(1-r m)\right\}$

$+i c \lambda\left\{\frac{1}{2}+2\left(\frac{A}{3}-\frac{A^{\prime}}{6}\right) T+3\left(\frac{B+B^{\prime}}{3}-\frac{A A^{\prime}}{4}\right) T^{2}+4\left(\frac{A B^{\prime}-A^{\prime} B}{6}\right) T^{3}+\frac{5 B B^{\prime}}{9} T^{4}\right\}=0$

or

$$
\begin{aligned}
& 20 i B B^{\prime}+24 i\left(A B^{\prime}-A^{\prime} B\right) T^{5}+3 i\left\{12\left(B+B^{\prime}\right)-9 A A^{\prime}\right\} T^{4} \\
& +\left\{24 B-24 r m B+2 i\left(12 A-6 A^{\prime}\right)\right\} T^{3}+18(A+i-r m A) T^{2}-\frac{36 A_{1}}{c \lambda}=0
\end{aligned}
$$

Solving equation (14), for T we get optimal (minimum) cycle time $\mathrm{T}=T_{2}$ and corresponding optimal (minimum) order quantity

$$
Q=Q_{2}=\lambda\left(T_{2}+\frac{A}{2} T_{2}^{2}+\frac{B}{3} T_{2}^{3}\right)
$$

And corresponding optimal (minimum) present value of all future cash-flows $Z_{2}(T)=Z_{2}\left(T_{2}\right)$ can be obtained from equation (11).

\section{Numerical Examples}

\section{Case 1: Example 1}

Let $\lambda=1500 ; A_{1}=250 ; i=0.20 ; \alpha=0.2, \beta=0.03, c=20, \gamma=0.3$ and $r=0.15$, in appropriate units. The variation of the optimal solution for different values of $r$ are shown in table 1 , where $T_{1}$ in years and $Z_{1}\left(T_{1}\right)$ in rupees.

\section{Case 2: Example 2}

Using all parameters in example (1) the variation of the optimal solution for different values of ' $\mathrm{m}$ ' and ' $\mathrm{r}$ ' is shown in table 2 , where $\mathrm{T}_{2}$ in years and $\mathrm{m}$ in days and $\mathrm{Z}_{2}\left(\mathrm{~T}_{2}\right)$ in rupees. The net discount rate per unit time ' $r$ ' is taken for item with large quantity where no political disturbances occurs, deterioration rate is constant and very small. Now these days there is a risk to store items for a long time due to discount rate per unit time ' $r$ ' fluctuates (high and low) day by day. The data for discount rate per unit time ' $r$ ' is taken in literature survey $[28,29]$.

\section{Sensitivity Analysis}

All the above can be summed up as follows:

From table 1, It can be easily seen that increase of ' $r$ ' results, slight increase of $\mathrm{T}_{1}, \mathrm{Q}_{1}$ but $\mathrm{Z}_{1}\left(\mathrm{~T}_{1}\right)$ constant.

From table 2, we see that

\begin{tabular}{|l|l|l|l|l|l|l|l|l|}
\hline$r$ & 0.17 & 0.19 & 0.21 & 0.23 & 0.25 & 0.27 & 0.29 & 0.31 \\
\hline $\mathrm{T}_{1}$ & 0.14996 & 0.15000 & 0.15004 & 0.15008 & 0.15012 & 0.15016 & 0.15019 & 0.15023 \\
\hline $\mathrm{Q}_{1}$ & 233.638 & 233.701 & 233.765 & 233.826 & 233.888 & 233.949 & 234.010 & 234.070 \\
\hline$Z_{1}\left(T_{1}\right)$ & 222047 & 222047 & 222047 & 222047.1 & 222047.1 & 222047.1 & 222047.1 & 222047.1 \\
\hline \multicolumn{8}{|c|}{ Table1: Optimal values of $\mathrm{T}_{1}, \mathrm{Q}_{1}$ and $\mathrm{Z}_{1}\left(\mathrm{~T}_{1}\right)$ for different values of $\mathrm{r}}$.
\end{tabular}


Citation: Tripathi RP, Shukla HS, Shukla V, Yadav SK (2012) Economic Ordering Policies of Linearly Time-Dependent Deteriorating Items with an Exponential Demand Rate under Credit Financing. J Applied Computat Mathemat 1:119. doi:10.4172/2168-9679.1000119

Page 4 of 5

\begin{tabular}{|c|c|c|c|c|c|c|c|c|c|}
\hline \multicolumn{2}{|c|}{$r$} & \multirow[t]{2}{*}{0.17} & \multirow[t]{2}{*}{0.19} & \multirow[t]{2}{*}{0.21} & \multirow[t]{2}{*}{0.23} & \multirow[t]{2}{*}{0.25} & \multirow[t]{2}{*}{0.27} & \multirow[t]{2}{*}{0.29} & \multirow[t]{2}{*}{0.31} \\
\hline \multicolumn{2}{|l|}{$\mathrm{m}$} & & & & & & & & \\
\hline \multirow[t]{3}{*}{60} & 0.15144 & 0.15165 & 0.15187 & 0.15209 & 0.15231 & 0.15253 & 0.15275 & 0.15297 & 0.15275 \\
\hline & 236.02 & 236.37 & 236.72 & 237.08 & 237.43 & 237.79 & 238.15 & 238.50 & 238.15 \\
\hline & 216238 & 215555 & 214871 & 214188 & 213504 & 212820 & 212137 & 211453 & 212137 \\
\hline \multirow[t]{3}{*}{90} & 0.15219 & 0.15250 & 0.15281 & 0.15313 & 0.15344 & 0.15376 & 0.15408 & 0.15440 & 0.15408 \\
\hline & 237.24 & 237.74 & 238.25 & 238.76 & 239.27 & 239.78 & 240.30 & 240.82 & 240.30 \\
\hline & 213333 & 212308 & 211282 & 210256 & 209231 & 208205 & 207179 & 206153 & 207179 \\
\hline \multirow[t]{3}{*}{120} & 0.15296 & 0.15336 & 0.15377 & 0.15419 & 0.15460 & 0.15502 & 0.15544 & 0.15587 & 0.15544 \\
\hline & 238.48 & 239.14 & 239.80 & 240.47 & 241.15 & 241.83 & 242.51 & 243.20 & 242.51 \\
\hline & 210427 & 209060 & 207692 & 206324 & 204956 & 203588 & 202220 & 200852 & 202220 \\
\hline \multirow[t]{3}{*}{150} & 0.15373 & 0.15424 & 0.15475 & 0.15527 & 0.15579 & 0.15631 & 0.15685 & 0.15738 & 0.15685 \\
\hline & 239.74 & 240.56 & 241.39 & 242.22 & 243.07 & 243.92 & 244.79 & 245.66 & 244.79 \\
\hline & 207521 & 205811 & 204101 & 202391 & 200681 & 198970 & 197259 & 195548 & 197259 \\
\hline \multirow[t]{3}{*}{180} & 0.15452 & 0.15513 & 0.15575 & 0.15637 & 0.15700 & 0.15764 & 0.15829 & 0.15894 & 0.15829 \\
\hline & 241.02 & 242.00 & 243.00 & 244.01 & 245.04 & 246.08 & 247.13 & 248.19 & 247.13 \\
\hline & 204614 & 202562 & 200510 & 198457 & 196404 & 194350 & 192297 & 190243 & 192297 \\
\hline \multirow[t]{3}{*}{210} & 0.15532 & 0.15604 & 0.15676 & 0.15750 & 0.15824 & 0.15900 & 0.15977 & 0.160551 & 0.15977 \\
\hline & 242.32 & 243.48 & 244.65 & 245.85 & 247.06 & 248.29 & 249.53 & 250.80 & 249.53 \\
\hline & 201707 & 199312 & 196917 & 194522 & 192126 & 189729 & 187332 & 184935 & 187332 \\
\hline \multirow[t]{3}{*}{240} & 0.15614 & 0.15696 & 0.15780 & 0.15865 & 0.15952 & 0.16040 & 0.16129 & 0.16220 & 0.16129 \\
\hline & 243.64 & 244.97 & 246.33 & 247.72 & 249.13 & 250.56 & 252.01 & 253.49 & 252.01 \\
\hline & 198799 & 196062 & 193324 & 190585 & 187846 & 185106 & 182366 & 179625 & 182366 \\
\hline \multirow[t]{3}{*}{270} & 0.15696 & 0.15790 & 0.15886 & 0.15983 & 0.16082 & 0.16183 & 0.16286 & 0.16391 & 0.16286 \\
\hline & 244.98 & 246.50 & 248.05 & 249.63 & 251.25 & 252.89 & 254.57 & 256.28 & 254.57 \\
\hline & 195890 & 192810 & 189729 & 186647 & 183565 & 180482 & 177398 & 174313 & 177398 \\
\hline \multirow[t]{3}{*}{300} & 0.15780 & 0.15886 & 0.15994 & 0.16104 & 0.16216 & 0.16331 & 0.16448 & 0.16568 & 0.16448 \\
\hline & 246.34 & 248.06 & 249.81 & 251.60 & 253.42 & 255.29 & 257.20 & 259.15 & 257.20 \\
\hline & 192981 & 189558 & 186134 & 182708 & 179282 & 175855 & 172427 & 168998 & 172427 \\
\hline \multirow[t]{3}{*}{330} & 0.15866 & 0.15984 & 0.16104 & 0.16227 & 0.16353 & 0.16482 & 0.16614 & 0.16750 & 0.16614 \\
\hline & 247.73 & 249.64 & 251.60 & 253.60 & 255.661 & 257.76 & 259.91 & 262.13 & 259.91 \\
\hline & 190071 & 186305 & 182537 & 178768 & 174998 & 171227 & 167455 & 163682 & 167455 \\
\hline
\end{tabular}

Table 2: Optimal values of $T_{2}, Q_{2}$ and $Z_{2}\left(T_{2}\right)$ for different values of $m$ and $r$.

a) Increase of ' $r$ ' results, increase of $T_{2}, Q_{2}$ and $Z_{2}\left(T_{2}\right)$ keeping ' $m$ ' constant.

b) Increase of ' $m$ ' results, increase of $T_{2}, Q_{2}$ and decrease of $Z_{2}\left(T_{2}\right)$ keeping ' $r$ ' constant.

\section{Conclusion and Future Research}

This paper deals with the problem of determining the present value of all future cash flows for linearly time- dependent deteriorating items for exponential time dependent demand rate. Two different cases have been discussed by considering the Discounted Cash Flow (DCF) approach for finding minimum future value of all cash flow. Truncated Taylor's series is used to find closed form optimal (minimum) solution for both cases i.e. case (1) Instantaneous cash flows and case (2) Fixed credit period. The net discount rate of inflation is taken for short interval of time for the item whose deterioration rate is constant and very small. Sensitivity analysis shows that the changes are quite sensitive for changing the parameters ' $r$ ' and ' $m$ '.

This paper can be extended in several ways. For instance we may extend this paper as demand rate is quadratic time dependent as well as stock- dependent. This paper can also be extended for allowing shortages. Finally, we could generalize the model for inflation dependent demand and freight charges etc.

\section{Appendix}

$$
\text { The solution of }(1) \text { is } I(t) e^{\alpha t+\frac{\beta}{2} t^{2}}=C-\int e^{(\alpha+\gamma) t+\frac{\beta}{2} t^{2}} d t
$$

$$
\left[e^{(\alpha+\gamma) t+\frac{\beta}{2} t^{2}}=1+(\alpha+\gamma) t+\left\{\frac{\beta+(\alpha+\gamma)^{2}}{2}\right\} t^{2}, \text { Approx } .\right]
$$

With this approximation, we get $I(t) e^{\alpha t+\frac{\beta}{2} t^{2}}=C-\lambda\left\{t+\frac{A}{2} t^{2}+\frac{B}{3} t^{3}\right\}$

where, $A=(\alpha+\gamma) \& B=\frac{\beta+(\alpha+\gamma)^{2}}{2}$, and $\mathrm{C}$ is the constant of integration.

Using condition $I(T)=0$, we get the solution

$$
I(t)=\lambda\left\{(T-t)+\frac{A}{2}\left(T^{2}-t^{2}\right)+\frac{B}{3}\left(T^{3}-t^{3}\right)\right\} e^{-\alpha t-\frac{\beta}{2} t^{2}}
$$

\section{Acknowledgements}

The authors would like to thank the referees for their valuable comments and suggestions that greatly helped to improve the earlier version of this research to present state. All of their suggestions were taken care of and incorporated in to the manuscript

\section{References}

1. Goyal SK (1985) Economic order quantity under conditions of permissible delay in payments. J Oper Res Soc 36: 335-338.

2. Chung KJ (1998) A theorem on the determination of economic order quantity under condition of permissible delay in payments. Comput Oper Res 25: 49-52.

3. Dave U (1985) On "economic order quantity under conditions of permissible delay in payments" by Goyal. J Oper Res Soc 36: 1069.

4. Aggarwal SP, Jaggi CK (1995) Ordering policies of deteriorating items under permissible delay in payments. J Oper Res Soc 46: 658-662. 
Citation: Tripathi RP, Shukla HS, Shukla V, Yadav SK (2012) Economic Ordering Policies of Linearly Time-Dependent Deteriorating Items with an Exponential Demand Rate under Credit Financing. J Applied Computat Mathemat 1:119. doi:10.4172/2168-9679.1000119

Page 5 of 5

5. Jamal AMM, Sarkar BR, Wang S (1997) An ordering policy for deteriorating items with allowable shortage and permissible delay in payment. J Oper Res Soc 48: 826-833.

6. Liao HC, Tsai CH, Su CT (2000) An inventory model with deteriorating items under inflation when a delay in payment is permissible. Int $\mathrm{J}$ Prod Econ 63 : 207-214

7. Teng JT (2002) On the economic order quantity under conditions of permissible delay in payments. J Oper Res Soc 53: 915-918.

8. Chang CT, Ouyang LY, Teng JT (2003) An EOQ model for deteriorating items under supplier credits linked to order quantity. Appl Math Model 27: 983-996.

9. Teng JT, Chang CT, Goyal SK (2005) Optimal pricing and Ordering policy under permissible delay in payments. Int J Prod Econ 97: 121-129.

10. Hwang H, Shinn SW (1997) Retailers pricing and lot sizing policy for exponentially deteriorating products under the condition of permissible delay in payments. Comput Oper Res 24: 539-547.

11. Tripathy CK, Mishra U (2011) Ordering policy for linear deteriorating items for declining demand with permissible delay in payments. Int $\mathrm{J}$ Open Problems Compt Math 4: 152-160.

12. Tripathi RP, Kumar M (2011) Credit financing in economic ordering policies of time-dependent deteriorating items. International Journal of Business, Management and Social Sciences 2: 75-84.

13. Jamal AMM, Sarker BR, Wang S (2000) Optimal payment time for a retailer under permitted delay of payment by the wholesaler. Int J Prod Econ 66: 59-66.

14. Teng JT, Min J, Pan Q (2012) Economic order quantity model with trade credit financing for non-decreasing demand. Omega 40: 328-335.

15. Tripathy CK, Mishra U (2010) An inventory model for Weibull time-dependen demand rate with completely backlogged. Int Math Forum 5: 2675-2687.

16. Hung KC (2011) An inventory model with generalized type demand, deterioration and backorder rates. Eur J Oper Res 208: 239-242.

17. Sana SS (2010) Optimal selling price and lotsize with time varying deterioration and partial backlogging. Appl Math Comput 217: 185-194
18. Khanara S, Ghosh SK, Chaudhuri KS (2011) An EOQ model for a deteriorating items with time-dependent quadratic demand under permissible delay in payment. Appl Math Comput 218: 1-9.

19. Sarkar B (2012) An EOQ model with delay in payments and time varying deterioration rate. Math Comput Model 55: 367-377.

20. Ouyang LY, Chang CT, Teng JT (2005) An EOQ model for deteriorating items under trade credits. J Oper Res Soc 56: 719-726.

21. Yang HL, Teng JT, Chorn MS (2010) An inventory model under inflation for deteriorating items with stock- dependent consumption rate and partia backlogging shortages. Int J Prod Econ 123: 8-19.

22. Chung KJ, Liao JJ (2009) The optimal ordering policy of the EOQ model under trade credit depending on the ordering quantity from the DCF approach. Eur $J$ Oper Res 196: 563-568.

23. Chung KH (1989) Inventory control and trade credit revisited. J Oper Res Soc 40: $495-498$

24. Dye CY, Ouyang LY, Hsieh TP (2007) Inventory and pricing strategies for deteriorating items with shortages: A discounted cash flow approach. Comput Ind Eng 52: 29-40.

25. Hsieh TP, Dye CY (2010) Pricing and lot-sizing policies for deteriorating items with partial backlogging under inflation. Expert Syst Appl 37: 7234-7242.

26. Chung KJ, Liao JJ (2006) The optimal ordering policy in a DCF analysis fo deteriorating items when trade credit depends on the order quantity. Int J Prod Econ 100: 106-130.

27. Hill RM, Pakkala TPM (2005) A discounted cash flow approach to the base stock inventory model. Int J Prod Econ 93: 439-445.

28. Jaggi CK, Aggarwal KK, Goel SK (2006) Optimal order policy for deteriorating items with inflation induced demand. Int J Prod Econ 103: 707-714.

29. Jaggi CK, Goyal SK, Goel SK (2008) Retailer's optimal replenishment decisions with credit-linked demand under permissible delay in payments. Eur J Oper Res 190: 130-135 